\title{
Kinetics of 1-dodecanethiol Desulfurization by Reactive Adsorbtion on MgO/dolomite
}

\author{
CONSTANTIN SORIN ION ${ }^{1}$, MIHAELA BOMBOS ${ }^{2 *}$, RAMI DOUKEH ${ }^{1}$, GABRIEL VASILIEVICI, VASILE MATEI ${ }^{1}$ \\ ${ }^{1}$ Petroleum-Gas University of Ploiesti, 39 Bucuresti Blvd., Ploiesti 100680, Romania \\ ${ }^{2}$ National Research Institute for Chemistry and Petrochemistry, ICECHIM, Spl. Independentei 202, 060021, Bucharest, \\ Romania
}

\begin{abstract}
Desulfurisation of 1-dodecanethiol was performed by adsorption process on MgO adsorbent. The adsorbant was characterized by determining the adsorption isotherms, specific surface area, pore volume and average pore diameter. Adsorption experiments were performed in continuous system at $300-450^{\circ} \mathrm{C}, 5 \mathrm{~atm}$ and volume hourly space velocities of $1 . . .2 h^{-1}$. Conversion of 1-dodecanetol increases with increasing temperature and decreasing volume hourly space velocities. It was identified the stage determinant of the process and a kinetic study of the desulfurization process was developed by reactive adsorption of 1-dodecanethiol on a magnesium oxide adsorbent.
\end{abstract}

Keywords: adsorptive desulphurization, kinetic, 1-dodecantiol, MgO adsorbent

Removing sulfur compounds during oil refining operations to obtain different petroleum products is not a simple process and it is becoming more and more difficult to achieve as the sulfur concentration imposed by European standards is lower. The three types of fuel: diesel, gasoline and airplane fuel contain various sulfur compounds. Thus, gasoline contains mercaptans, sulfides and thiophenes, while diesel contains benzothiophenes, dibenzothiophenes and derivatives thereof. Conventionally, hydrodesulfurization is used to reduce the sulfur concentration of liquid fuels [1-6]. This process requires suitable catalysts for the removal of sulfur compounds and occurs at high temperatures, for example at $450^{\circ} \mathrm{C}$ and at elevated pressures, 20-40 atm. There are also disadvantages of the hydrodesulfurization process, such as high costs, but also the decrease in fuel efficiency by lowering the octane number due to saturation of aromatic or olefinic groups. Other alternative solutions to this problem, such as desulphurization using adsorption, oxidation or desulphurization, have to be evaluated.

Desulfurization using adsorption is a promising method, butthe interaction of sulfur compounds with the adsorbent surface, which plays a crucial role in eliminating them, is not yet well known. This implies an improvement in the knowledge about the adsorption behavior of differentsulfur compounds on different adsorbent surfaces, the size and effectiveness of new materials used for intense desulphurisation.

Desulfurization by adsorption can remove sulfur compounds by physical adsorption or chemosorption. The adsorption process using activated charcoal forms and modified adsorbents can be an excellent technique that combined with the hydrodesulfurization technique can lead to the production of diesel and other fuels with a imposed sulfur content. A disadvantage of the adsorption desulfurization method is that it does not eliminate the impurities and the composition of the fuel remains essentially the same.

The classical adsorption process is expected to exhibit a selective elimination of sulfur compounds under the usual conditions which facilitates process control and allows for the elimination of sulfur compounds at much lower costs. Easy regeneration of the adsorbent material with a minimum of chemical and energetic effort is essential to using this technology. Specialist literature mentions many successful adsorbents and unsatisfactory others. Adsorbents impregnated with transition metals such as nickel, iron, copper, zinc, palladium are considered effective in removing sulfur compounds. In the studies conducted for numerous separation or purification processes including industrial applications, solid adsorbent substances were used, such as: active carbon, zeolite, silver-impregnated membranes, polymeric adsorbents, etc. These substances have been used due to their high surface area and good adsorption capacity.

The commercial availability of numerous adsorbents with different adsorption capabilities and various porous structures requires a careful selection of the best variants. Selection of adsorbents has been made in view of polarity interactions to obtain improvements in desulphurisation performance [7].

The removal of sulfur by $\mathrm{Ni} / \mathrm{NiO}$ sorbents is basically feasible for both high sulfur and low content fuels. The optimal temperature range for this process is between 200$220^{\circ} \mathrm{C}$ when a desulphurisation degree of $<0.2 \mathrm{ppm}$ is obtained and varies with contact time. Therefore, desulphurisation with $\mathrm{Ni} / \mathrm{NiO}$ sorbent is suitable and adaptable for all desulphurisation processes. Determination of optimum operating conditions has shown that the adsorption desorption process using nickel-based adsorbents is independent are: temperature of $200^{\circ} \mathrm{C}$ and 5 bar pressure to achieve a low sulfur content of $<1 \mathrm{mg} \mathrm{kg}$ 1 for commercial liquid fuels such as gasoline, diesel and oil used to heat homes.

Adsorbent desulfurization takes place in the same mechanism as hydrodesulfurization. The difference between the two processes lies in the supply of hydrogen; During the adsorption process an internal supply of hydrogen takes place, while in the case of hydrodesulphurization there is an external supply. [8]

Generally, when desulphurizing high sulfur fuels (850ppm), the adsorbents have a higher adsorption capacity due to the lower dibenzothiophene fraction. Moreover, the influence of the operating temperature in the selective adsorption process of sulfur has been studied using several types of commercial fuels. Thus, for complete 
desulphurization of DBT with a single alkyl group, an operating temperature of $100^{\circ} \mathrm{C}$ is sufficient. At temperatures above $200^{\circ} \mathrm{C}$ desulphurization occurs even of the sulfur-containing species found in traces such as 4,6-DMDBT (4,6-dimethyl-dibenzothiophene) and 1,4,6TMDBT (1,4,6- trimethyl-dibenzothiophene).

Therefore, the desulphurization process presented is suitable for low-sulfur fuels: petrol and diesel. Due to the low adsorption capacity, desulphurization of high sulfur fuels is not recommended. The activity and capacity of adsorbents should be improved until the technique can be applied to modern fuel desulphurization systems [9].

Although there are many studies that address the hydrodesulfurization, the number of publications that address the desulfurization by chemical adsorption is relatively low. In this paper we studied the reactive desulfurization of 1-dodecanethiol to reduce the load of hydrodesulfurization stage.

\section{Experimental part}

\section{Chemicals}

The raw materials used in experiments were magnesium oxide powdered Sigma-Aldrich, native bentonite powdered, nitrogen purity from Linde Company and 1-dodecanethiol ( $\geq 98 \%$ Aldrich).

\section{Adsorbent preparation}

Adsorbent granulation was performed by mixing the mixture of bentonite and magnesium oxide powders, at a magnesium oxide / bentonite mass ratio of 30/70, in the presence of water. Add distilled water and continue mixing in the mixer approx. $60 \mathrm{~min}$. to obtain the necessary consistency for extrusion in a manual extruder through the nozzle of $2 \mathrm{~mm}$ diameter. After the extrusion have been obtained, they are air-dried for $24 \mathrm{~h}$, then dried at an aircirculation oven at $160^{\circ} \mathrm{C}$ for 6 hours. The adsorbent so prepared was stored in the desiccator until use.

\section{Adsorbent characterization}

Chemical composition and textural characteristics of bentonite used in the experimental program was presented in $[10,11]$. Adsorbent characterization was performed by determining the textural characteristics (surface area, pore volume, average pore diameter, pore-size-distribution) on Autosorb 1 Quantacrome. The specific surface area was calculated using the equation in the linear part of the BET desorption isotherm. The distribution of pores and the pore size was determined by processing the desorption branch of isotherms with hysteresis, applying the $\mathrm{BJ} \mathrm{H}$ method.

The experimental data required to achieve the kinetic study were obtained on fixed bed reactor in isothermal conditions presented in recent scientific papers [10,11].

Reaction conditions were:

-pressure: 5 bar;

-temperature: $300-450^{\circ} \mathrm{C}$;

-volume hourly space velocities (VHSV): $1 . .2 \mathrm{~h}^{-1}$;

-nitrogen/ raw material ratio: $400 \mathrm{Nm}^{3} / \mathrm{m}^{3}$.

The composition of the starting material and reaction products was determined by the GC-MS method, using a GC / MSTriple Quad Agilent Technology, using a NIST library to identify the compounds.

\section{Results and discussions}

The texture of the magnesium oxide - bentonite adsorbent used in the experimental program is presented in the table 1. The specific surface area and medium pore diameter of the adsorbent has a typical value for bentonitebased adsorbents.

Figures 1 and 2 show pore size distribution and adsorption isotherm of the adsorbent. It observed that the adsorbent possesses a well-defined large pore size and a maximum distribution centered around $40 \AA$, suggesting a high content of mesopores.

The variation of 1-dodecanethiol conversion with temperature at a pressure of 5 bar is shown in figure 3 . Thus, conversion of 1-dodecanetol increases with increasing temperature and decreasing volume hourly space velocities from a minimum of $30.59 \%$ at $300{ }^{\circ} \mathrm{C}$ and $2 h^{-1}$ to a maximum of $95.97 \%$ at $450{ }^{\circ} \mathrm{C}$ and a $1 h^{-1}$.

The influence of the volume hourly space velocities on the conversion of 1-dodecanethiol at the 5 bar pressure is shown in figure 4.

Conversion of 1-dodecanethiol decreases with increasing of the volume hourly space velocities (fig. 4), which is strongly influenced by the increase of the

\begin{tabular}{|c|c|c|c|}
\hline Adsorbent & $\begin{array}{c}\text { Specific surface area, } \\
\left(\mathbf{~ m}^{2} / \mathrm{g}\right)\end{array}$ & $\begin{array}{c}\text { Pore volume, } \\
\left(\mathrm{cm}^{\mathbf{3}} / \mathrm{g}\right)\end{array}$ & $\begin{array}{c}\text { Medium pore diameter } \\
(\mathbf{n m})\end{array}$ \\
\hline $\mathrm{MgO} /$ bentonite & 89.902 & 0.154 & 4,031 \\
\hline
\end{tabular}

Table 1

TEXTURAL CHARACTERISTICS OF ADSORBENT

Fig.1. Pore size distribution of $\mathrm{MgO}$ / bentonite 


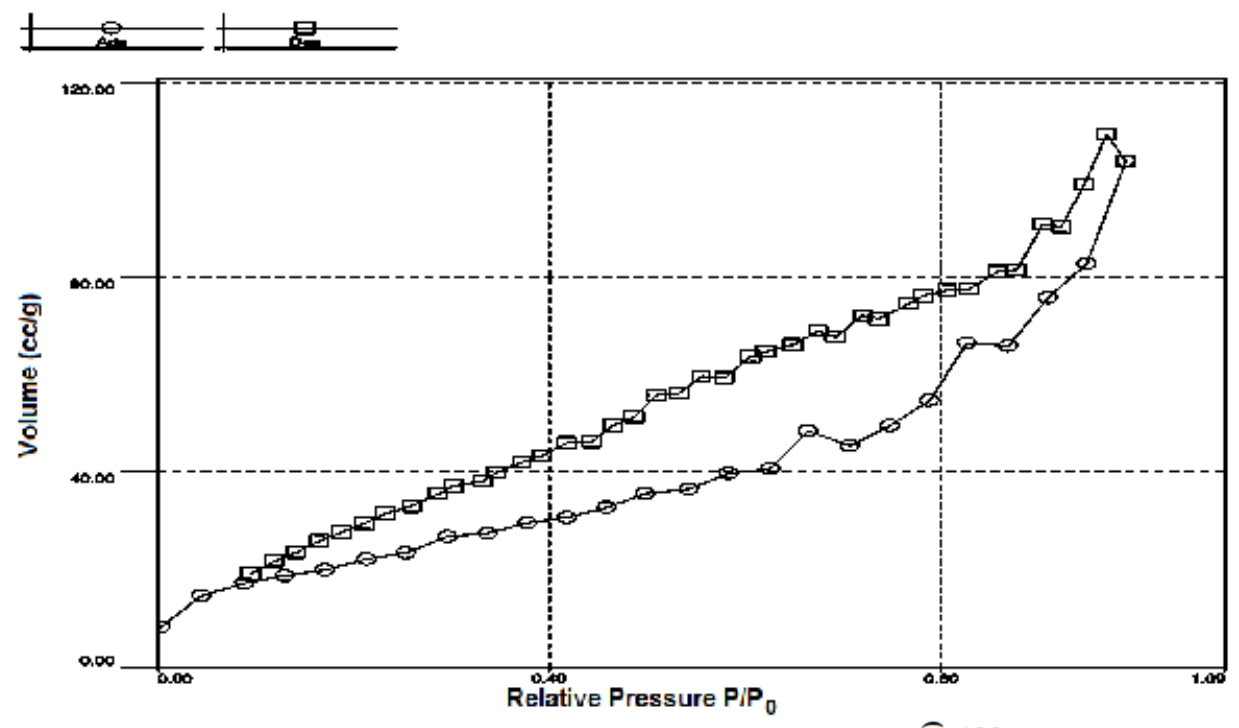

Fig.2. Adsorption isotherm of the adsorbent

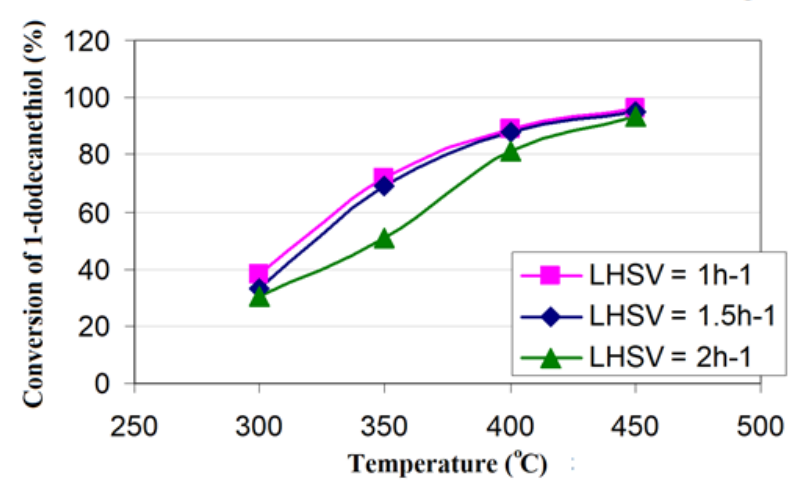

Fig.3. Conversion of 1-dodecanethiol with temperature

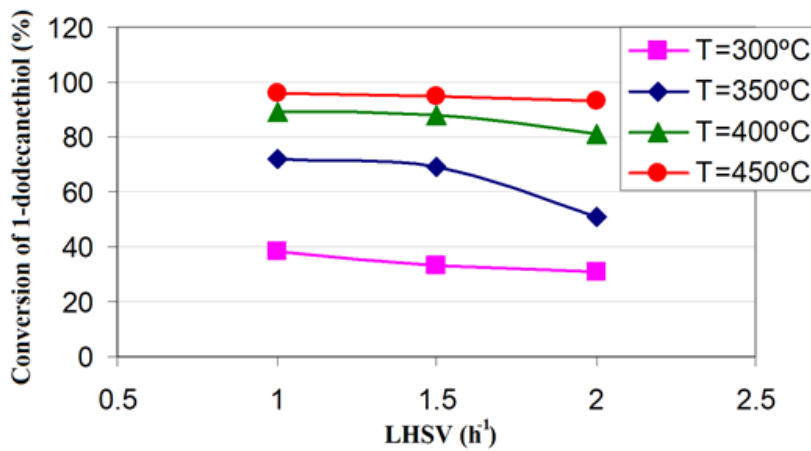

Fig.4. The influence of the volume hourly space velocities on the conversion of 1-dodecantiol

temperature. Under the given working conditions, 1-dodecanethiol conversion has values in a wide range, ranging from 30.59 to $95.97 \%$.

\section{Kinetics of desulphurisation process}

The process of desulphurization of aliphatic thiols is assumed to proceed in two steps. Thus, the proposed reaction mechanism assumes that the process takes place in two steps, respectively in the first step the elimination of the sulfhydric acid occurs with the formation of an olefin (a) and in the second the sulfhydric acid is neutralized by the metal oxide present in the pores of the adsorbent (b):

$$
\begin{aligned}
& \mathrm{R}-\mathrm{SH} \rightarrow \mathrm{R}_{2}+\mathrm{H}_{\mathrm{S}} \mathrm{S} \\
& \mathrm{H}_{2} \mathrm{~S}+\mathrm{MgO} \rightarrow \mathrm{MgS}+\mathrm{H}_{2} \mathrm{O}
\end{aligned}
$$

where: R1 - alkene

$$
\mathrm{R} \text { - the alkyl group }
$$

In order to represent the global desulfurization process by reactive adsorption, it is assumed that the rate-determining step is the step of removing sulfhydric acid. This hypothesis is based on the fact that the neutralization reaction of hydrogen sulphide with magnesium oxide is an instantaneous reaction (acid-base neutralization reaction).

The process of desulphurization by reactive adsorption of 1-dodecanethiol on the $\mathrm{MgO}$ adsorbent takes place with the formation of 1-dodecene and 2,3-dimethyl-3-decene, which shows that it occurs according to the reactions:

$$
2 \mathrm{H}_{3} \mathrm{C} \overbrace{\text { dodecane-1-thiol }}^{1}=\mathrm{H}_{\text {dodec-1-ene }}^{\text {(2,3-dimethyldec-3-ene }}
$$

Considering that for the reaction of hydrogen sulphide elimination, the rate-determining step is the itself reaction on the surface of the adsorbent, the process steps are as follow

$$
\begin{aligned}
& \mathrm{RSH}+\Delta \stackrel{\mathrm{K}_{\text {RSH }}}{\longrightarrow} \mathrm{RSH} \Delta \\
& \mathrm{RSH} \Delta+\Delta \stackrel{\mathrm{k}_{1}}{\longrightarrow}-\mathrm{R}_{1} \mathrm{H} \Delta+\mathrm{H}_{2} \mathrm{~S} \Delta \\
& \mathrm{RSH} \Delta+\Delta \stackrel{\mathrm{k}_{2}}{=} \mathrm{R}_{2} \mathrm{H} \Delta+\mathrm{H}_{2} \mathrm{~S} \Delta
\end{aligned}
$$

$$
\begin{aligned}
& \mathrm{R}_{1} \mathrm{H} \Delta \stackrel{\mathrm{K}_{\mathrm{R}: \mathrm{u}} \rightleftharpoons}{\rightleftharpoons} \mathrm{R}_{1} \mathrm{H}+\Delta \\
& \mathrm{R}_{2} \mathrm{H} \Delta \stackrel{\mathrm{K}_{\mathrm{R} 2 \mathrm{H}}}{\rightleftharpoons} \mathrm{R}_{2} \mathrm{H}+\Delta \\
& \mathrm{H}_{2} \mathrm{~S} \Delta \rightleftharpoons \mathrm{K}_{2} \mathrm{~S}+\Delta
\end{aligned}
$$


where: RSH - dodecane-1-thiol

$\mathrm{R}_{1} \mathrm{H}$ - 1-dodecene

$\mathrm{R}_{2}^{1} \mathrm{H}$ - 2,3-dimethyl-3-decene

The expression of reaction speed is of the LHHW type, being represented by the equations:

$$
\begin{aligned}
& r_{1}=\frac{k_{1} K_{R S H} p_{R S H}}{\left(1+K_{R S H} p_{R S H}+K_{R_{1} H} p_{R_{1} H}+K_{R_{2} H} p_{R_{2} H}+K_{H_{2} S} p_{H_{2} S}\right)^{2}} \\
& r_{2}=\frac{k_{2} K_{R S H} p_{R S H}}{\left(1+K_{R S H} p_{R S H}+K_{R_{1} H} p_{R_{1} H}+K_{R_{2} H} p_{R_{2} H}+K_{H_{2} S} p_{H_{2} S}\right)^{2}}
\end{aligned}
$$

where: $k_{1}, k_{2}$ - reaction rate constants (mol / gads. s bar ${ }^{2}$ );

$\mathrm{K}_{\mathrm{i}}$ - ad'sorption equilibrium constants (bar $\left.{ }^{-1}\right)$;

$\mathrm{P}_{\text {- }}$ - partial pressure of the component i from the mixture (bar).

Partial pressures of components are calculated using the following relationships:

$$
\begin{aligned}
& p_{j}=P \frac{F_{j}}{\sum_{i=1}^{2} F_{j}} \\
& F_{j}=F_{J 0}+\sum_{i=1}^{r} v i_{j} \xi_{i}
\end{aligned}
$$

Since the experimental program was run on a displacement reactor (variable composition along the catalytic bed), it started from the hypothesis that the vapor flow regime is of the piston type. It has also been considered that temperature variations along the catalyst bed are negligible, the reaction regime being isothermal.

Evolution of the process in the reactor was described by the pseudo-homogeneous plunger-flow model. The variation in the composition of the reaction mixture along the catalyst bed is calculated with the mass balance equations written as:

$$
\frac{d \xi_{i}}{d m_{c a t}}=\left(-r_{i}\right)
$$

where: $\xi$-molar degree of molar reaction progress

$\left(-r_{i}\right)$-speed of reaction $\left(\mathrm{mol}^{-1} \mathrm{~s}^{-1} \mathrm{~kg}^{-1}\right)$

$\mathrm{m}_{\text {cat }}$ - adsorbent mass $(\mathrm{kg})$.

$$
k_{i}=A_{i} e^{\frac{E_{i}}{R T}}
$$

where: $k_{i}$ - constant speed of $\mathrm{i}$ reaction; $\mathrm{i}=1,2$ (mol. $\mathrm{s}^{-1}$. $\left.\mathrm{kg}^{-1} \cdot \mathrm{bar}^{-1}\right)$

Ei- activation energy ( $\mathrm{Kj} / \mathrm{mol})$;

T- temperature $(K)$;

A- preexponential factor; $\left(\mathrm{mol}^{-1} \mathrm{~s}^{-1} \mathrm{~kg}^{-1} \cdot \mathrm{bar}^{-1}\right)$.

$$
\begin{aligned}
& x_{R S H}=\frac{F_{R S H 0}-F_{R S H}}{F_{R S H 0}} \\
& \eta_{j}=\frac{F_{j}}{F_{R S H O}} \\
& F_{j}=F_{J 0}+\sum_{i=1}^{r} v i_{j} \xi_{i}
\end{aligned}
$$

\begin{tabular}{|c|c|c|c|c|c|}
\hline \multirow{2}{*}{ Temperature } & \multirow{2}{*}{ Presure } & \multirow{2}{*}{$\begin{array}{l}\text { Volume hourly } \\
\text { space velocities, }\end{array}$} & \multirow{2}{*}{$\begin{array}{l}\text { Conversion of } \\
\text { 1-dodecanethiol, }\end{array}$} & \multirow{3}{*}{$\begin{array}{c}\text { Yield in } \\
\text { 1-dodecene, } \\
(\%)\end{array}$} & \multirow{3}{*}{$\begin{array}{c}\text { Yield in } \\
\begin{array}{c}\text { 2,3-dimethyl-3-decene, } \\
(\%)\end{array}\end{array}$} \\
\hline & & & & & \\
\hline (K) & (bar) & & $\begin{array}{c}\text { 1-dodecanethiol, } \\
\text { (\%) }\end{array}$ & & \\
\hline 573 & 5 & 1 & 38.2378526 & 27.2524 & 11.0227414 \\
\hline 573 & 5 & 1.5 & 33.267056 & 18.5162 & 7.5804648 \\
\hline 573 & 5 & 2 & 30.5952529 & 13.2347 & 5.766124 \\
\hline 593 & 5 & 1 & 53.4981981 & 38.53 & 9.7054803 \\
\hline 623 & 5 & 1 & 72.0392693 & 47.32 & 19.83 \\
\hline 623 & 5 & 2 & 5.689698 & 25.96 & 14.3531751 \\
\hline 673 & 5 & 1 & 89.1885175 & 56.42 & 29.453 \\
\hline 723 & 5 & 1.5 & 95.0292034 & 39.9528 & 44.08 \\
\hline
\end{tabular}

where:P-total pressure (bar).

p--partial pressure of componentj (bar). reaction $\mathrm{i}$;

$v_{i j}$ - stoichiometric coefficient of the species $j$ in the

$F_{-j}$ - molar flow of component j ( $\mathrm{mol} / \mathrm{s}$ ).

In order to estimate the kinetic model parameters, the least squares method was used, the method focused on choosing the parameters of the kinetic model in such a
Table 2 EXPERIMENTAL DATA USED IN THE STUDY 


\begin{tabular}{|c|c|c|c|}
\hline Parameter & $\begin{array}{l}\text { Values estimated } \\
\text { with initial } \\
\text { expressions of } \\
\text { reaction rates }\end{array}$ & $\begin{array}{l}\text { Values estimated with } \\
\text { simplified expression of } \\
\text { reaction rates }\end{array}$ & $\begin{array}{c}\text { Unit of } \\
\text { measurement }\end{array}$ \\
\hline $\mathrm{A}_{1}$ & 0.39242 & 0.30646 & $\mathrm{~mol} \cdot \mathrm{s}^{-1} \mathrm{~kg}^{-1} \cdot \mathrm{bar}^{-1}$ \\
\hline $\mathrm{A}_{2}$ & 25.646 & 20.099 & $\mathrm{~mol}^{-1} \mathrm{~s}^{-1} \mathrm{~kg}^{-1} \cdot \mathrm{bar}^{-1}$ \\
\hline$\overline{E_{1}}$ & 45.948 & 46.134 & $\mathrm{~kJ} / \mathrm{mol}$ \\
\hline $\mathrm{E}_{2}$ & 71.486 & 71.690 & $\mathrm{~kJ} / \mathrm{mol}$ \\
\hline $\mathrm{K}_{\mathrm{RSH}}$ & 92.669 & 85.119 & $\mathrm{bar}^{-1}$ \\
\hline$\overline{\mathrm{K}_{\mathrm{R} H \mathrm{H}}}$ & $1.2549 \mathrm{e}-08$ & $1.3177 \mathrm{e}-08$ & $\mathrm{bar}^{-1}$ \\
\hline $\mathrm{K}_{\mathrm{R} 2 \mathrm{H}}$ & $8.4720 \mathrm{e}-02$ & $8.4729 \mathrm{e}-02$ & $\mathrm{bar}^{-1}$ \\
\hline $\mathrm{K}_{\text {H2S }}$ & 153.83 & 136.88 & $\mathrm{bar}^{-1}$ \\
\hline $\mathrm{R}^{2}$ (R-squer) & 0.97407 & 0.97404 & \\
\hline SSE & 0.035344 & 0.035344 & - \\
\hline
\end{tabular}

Table 3

PARAMETERS OF THE KINETIC MODEL way that minimizing an objective function (function of model error) defined as the sum of the squares of the differences between experimentally measured molar fractions and those calculated on the basis of of the proposed kinetic model of the reactant. The error function in the estimation process has the form:

$$
S E E=\sum\left(x_{i-\exp }-x_{i-\text { calc }}\right)^{2} \rightarrow \min
$$

where: $x_{i}$ - parameter (yield, conversion)

The experimental data used in the study are shown in table 2.

The parameters of the kinetic model proposed for the desulfurization of 1-dodecanethiol obtained after modeling are presented in table 3.

Values obtained for the $\mathrm{K}_{\mathrm{R} 1 \mathrm{H}}$ and $\mathrm{K}_{\mathrm{R} 2 \mathrm{H}}$ parameters show that these terms do not make an important contribution to the expression speeds. Thus the speed equations can be simplified to the form:

$$
\begin{aligned}
& r_{1}=\frac{k_{1} K_{R S H} p_{R S H}}{\left(1+K_{R S H} p_{R S H}+K_{H, S} p_{H, S}\right)^{2}} \\
& r_{2}=\frac{k_{2} K_{R S H} p_{R S H}}{\left(1+K_{R S H} p_{R S H}+K_{H_{2} S} p_{H_{2} S}\right)^{2}}
\end{aligned}
$$

The evaluation of the correlation of the experimental data with the proposed kinetic model is presented graphically (figs. 5-7). Differences between experimental and estimated values can be considered acceptable and the simplified expression of reaction speed of the type LHHW proposed, was optimal.

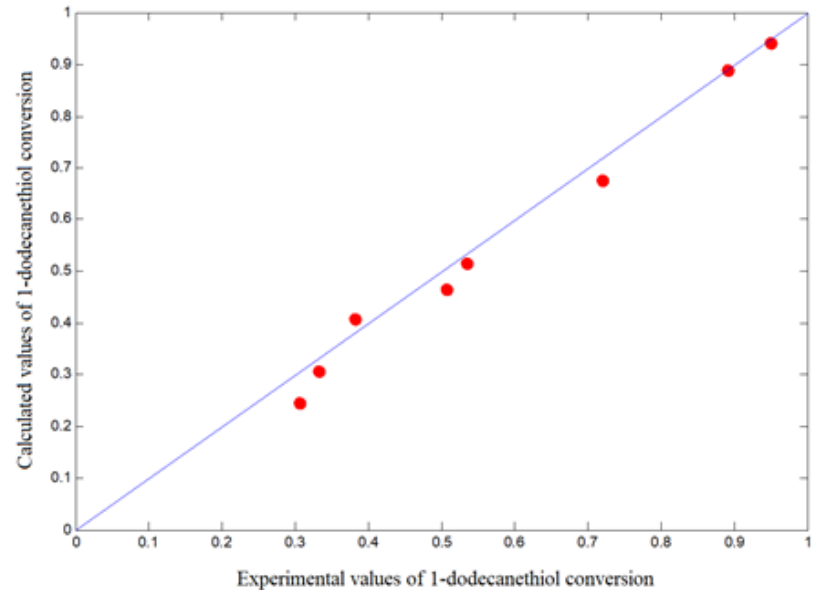

Fig.5. Experimental values of 1-dodecanethiol conversion versus calculated values

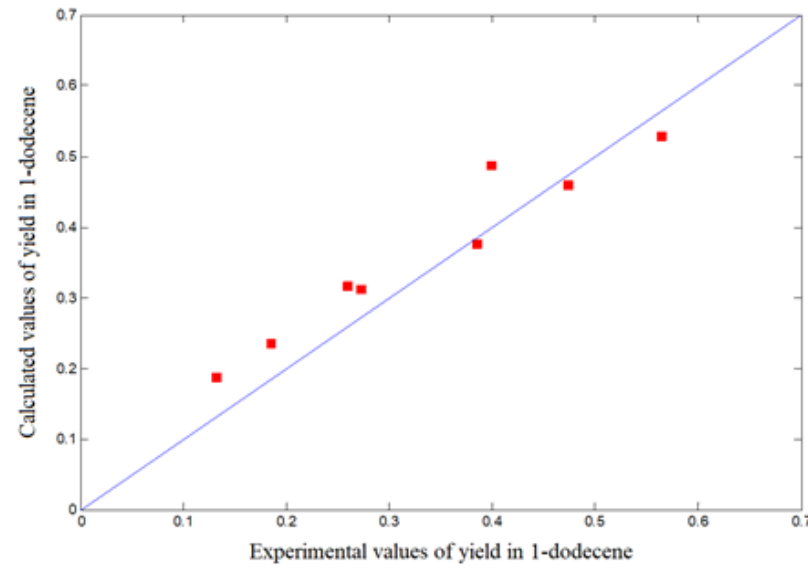

Fig.6. Experimental values of yield in 1-dodecene compared to calculated values 


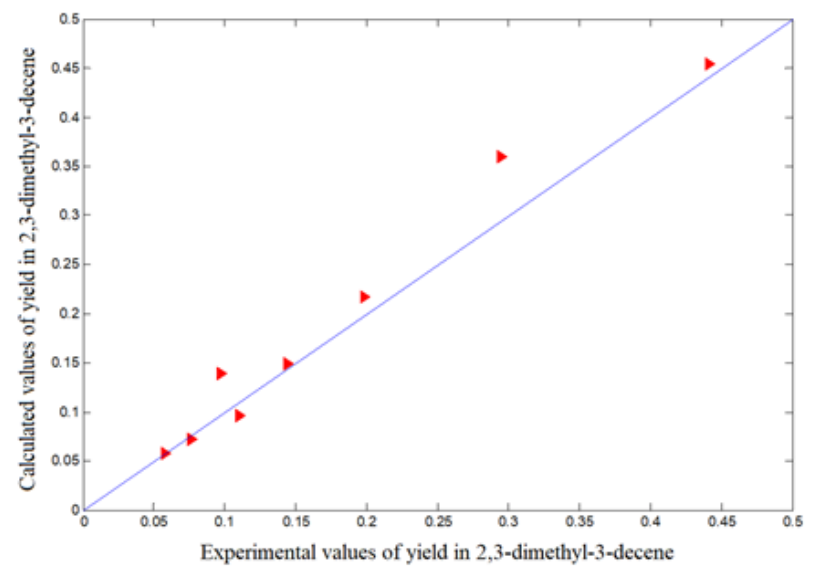

Fig.7. Experimental values of yield in 2,3-dimethyl-3-decene compared to calculated values

\section{Conclusions}

Desulfurization of 1-dodecanethiol was performed by reactive adsorption process on $\mathrm{MgO} /$ bentonite.

The adsorbant was characterized by determining the adsorption isotherms, specific surface area, pore volume and average pore diameter.

Adsorption experiments of 1-dodecanethiol was performed in continuous system at $300-450^{\circ} \mathrm{C}, 5 \mathrm{~atm}$ and volume hourly space velocities of $1-2 \mathrm{~h}^{-1}$.

The proposed reaction mechanism assumes that the process takes place in two steps, respectively in the first step the elimination of the sulfhydric acid occurs with the formation of an olefin (a) and in the second the sulfhydric acid is neutralized by the adsorbent.
It was identified the stage determinant of the process and a kinetic study of the desulfurization process was developed by reactive adsorption of 1-dodecanethiol on a magnesium oxide adsorbent.

Differences between experimental and estimated values can be considered acceptable and the simplified expression of reaction speed of the type LHHW proposed, was optimal.

\section{References}

1.GUPTA, N., ROYCHOUDHURY, K., DEB, J.K., Appl. Microbiol. Biotechnol., 66(4), 2005, p.356;

2.BABICH, I.V., MOULIJ N, J.A., Fuel, 82, 2003, p.607;

3.EL-GENDY, N. S., SPEIGHT, J . G., CRC Press, Taylor \& Francis Group, 2016;

4.SUN, Y., PRINS, R., Angew. Chem., Int,. 47, 2008, p.8478;

5.VILLA GARCIA, M. A., LINDNER, J., SACHDEV, A., SCHWANK, J., J. Catal.119, 1989, p.388;

6.DELMON, B., Catal. Lett., 22 (1-2),1993, p.1-3;

7.OLIVER VAN RHEINBERG, LUCKA, K., KÖHNE, H., Journal of Power Sources, 196, 2011, p. 8983;

8.PATIL S.V., SOROKHAIBAM L.G. , BHANDARI V. M., KILLEDAR D.J ., RANADE V. V., Journal of Environmental Chemical Engineering, 2, 2014, p.1495;

9. OLIVER VAN RHEINBERG, LUCKA K., KOHNE H., SCHADE T. , ANDERSSON J. T. , Fuel, 87, 2008, p. 2988;

10.ION C. S., BOMBOS M., VASILIEVICI G., PANAITESCU C., DRAGOMIR

R., Rev. Chim. (Bucharest), 68, no. 4, 2017, p.732;

11. ION C. S., BOMBOS M., VASILIEVICI G., BOMBOS D., Rev. Chim. (Bucharest), 68, no.3, 2017, p.483

$\overline{\text { Manuscript received: } 12.04 .2018}$ 